\title{
The Application of the SCT and the ANP Model to Refine the Most Critical ICT Determinants in Minimizing the Digital Divide
}

\author{
Ming-Yuan Hsieh \\ Department of International Business, National Taichung University of Education, Taichung 403, Taiwan \\ Correspondence should be addressed to Ming-Yuan Hsieh; uscpawisely@hotmail.com
}

Received 8 June 2014; Accepted 31 July 2014; Published 31 August 2014

Academic Editor: Teen-Hang Meen

Copyright (c) 2014 Ming-Yuan Hsieh. This is an open access article distributed under the Creative Commons Attribution License, which permits unrestricted use, distribution, and reproduction in any medium, provided the original work is properly cited.

This research cross-employed the social cognition theory (SCT) and the analytical network process (ANP) model in qualitative analyses and the multiple criteria decision making (MCDM) methodology in quantitative measurements to comprehensively reidentify the most critical information communication technology (ICT) determinants in minimizing the digital divide (DD). After measuring the complete importance of related priority weight $\mathbf{w}$ (eigenvector) from the survey results given to various experts, the complete synthetically comparative index numbers (SCIN) from the evaluation model used conveyed two distinct consequences. First, the highest SCIN scores for the ANP, F-ANP, and G-ANP models are 0.5516, 0.3771, and 0.4791, respectively, and are located in the "ICT can positively minimize the level of DD" (ICTCPMDD) column in the summarized results table. Secondly, the highest evaluated weighted score of assessed criteria of 0.5801 is located in the Diversified Mobile Applications (DMAPP) column. From these results, there are two contributive findings that can be deduced. First, ICT indeed proved the determinative influences and interplays in the level of DD which means that the undeveloped, developing, and emerging regions are apparently able to minimize the level of DD by means of the ICT development. Second, the Diversified Mobile Applications (DMAPP) is the most critical determinant of ICT in minimizing the level of digital divide.

\section{Introduction}

The swift progress in high-speed bandwidth, broadband, and wireless transmission of the information technology (IT) and telecommunication technology (TT), the information and communication technology (ICT) has rapidly been invented and developed [1]. With respect to the empirical world market of ICT industry, the 2013 annual official report of the global ICT industrial statistics published from the International Telecommunication Union (ITU) conveys the following three major points as expressed in Figures 1 and 2. (1) For the entire world, there are 96 mobile phones for every 100 persons. In the developed regions, that ratio is 126 per every 100 persons. The mobile phone ration in developing regions is 89 for every 100 persons. (2) In the emerging Africa regions, mobile phone penetration is only 63 for every 100 person and, (3) according to the latest accumulating statistics of the ITU, the mobile-cellular subscriptions in the entire
Asia-pacific regions has reached up to 3.5 billion populations as well as achieving half of the global 6.8 mobile-cellular subscriptions. Further statistics on the global ICT industry reveal five distinct and direct conclusions, as presented in Figure 3, which comprise the following: (1) the mobilecellular telephone subscriptions rate per 100 inhabitants has increased over 5 times in the last 10 years from 15.5 in 2001 to 86.7 in 2011 as expressed in the dark blue curve, (2) the global internet users rate per 100 inhabitants has increased around 4.4 times from 8 in 2001 to 34.7 in 2011 represented in the red curve, (3) the fixed telephone lines rate per inhabitant (shown in green) has declined slightly resulting from the popularizing use of mobile phones, (4) the active mobile-broadband subscriptions rate per inhabitant (shown in purple) experienced a significant growth from almost negligible in 2007 to 17 in 2011, and (5) the fixed (wired) broadband subscriptions rate per inhabitant (shown in light blue) has increased from 0.6 to 8.5 in the last 10 years 


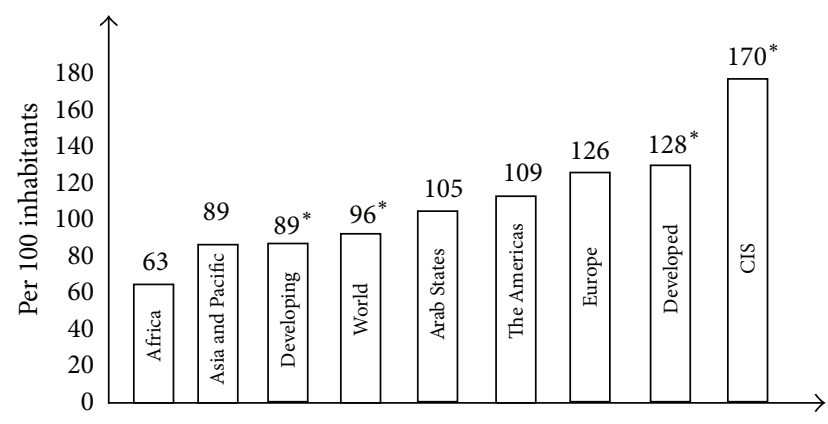

Source: ITU world telecommunication/ICT indicators database Note: * estimate

FIgURE 1: The global mobile-penetration in 2013.

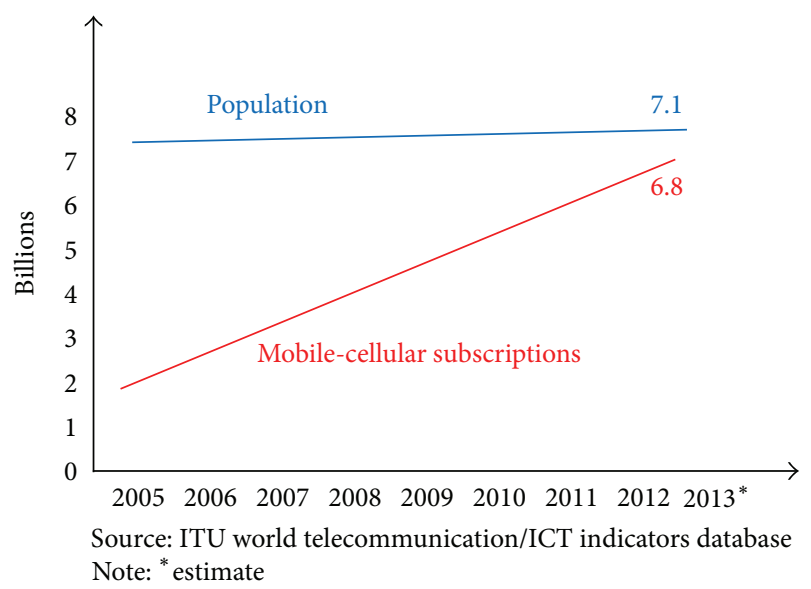

FIGURE 2: Relationship between the global population and mobilecellular subscriptions from 2009 to 2013. The global mobilepenetration in 2013.

as of 2011. Essentially, ICT was basically constructed from the cross applications of the internet feature in consumer electronic devices such as televisions, mobile phones, and global positioning systems (GPS) in order to satisfy the needs of computer users [2]. Furthermore, the internet has gradually and broadly been absorbed into people's life with the use of web-portals (such as Yahoo and Google), virtual social communities (such as Twitter and Facebook) as well as the individual consumer electronic devices (smart phones and tablets) [3]. Based on the specific operational characteristics of ICT, it is significantly easier for individuals to become ICT multi-users. Additionally, ICT users are able to manipulate the cross applied ICT apparatuses without space and time restrictions. These apparatuses have resulted in that the ICT consumer electronic devices have completely played a decisive role in people's lives [4]. As the popularity of ICT has expanded, a majority of recent researches have focused on the software and hardware functions of ICT [5]. Furthermore, the extensive ICT users have gotten custom to using mobile phones to surf internet websites, obtain GPS piloting and handle e-mails, and play online games with smart-phone application (APP) services in any location to

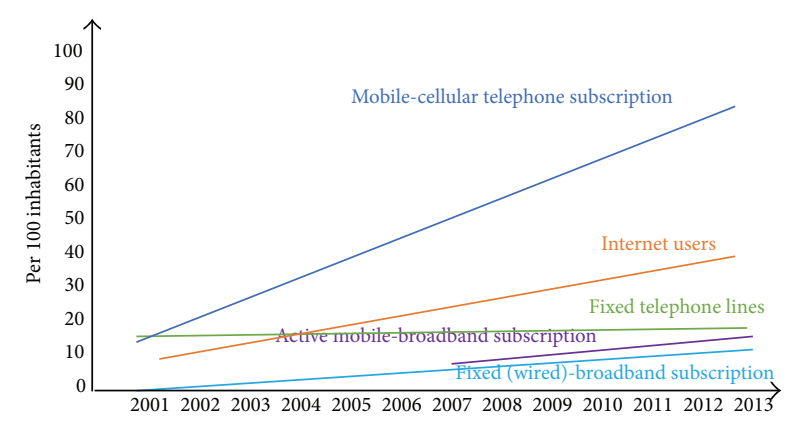

Source: ITU world telecommunication/ICT indicators database Note: * estimate

Figure 3: Global ICT relative industrial statistics.

provide their own various position information to each surfer in order to establish and condition their owned virtual social communities in anywhere and at any time.

However, with current rapid development in the ICT industries, the diversified economic and social-inequality digital cognitions between categories of individuals in a given population and their access to, use of, or knowledge of internet technology have resulted in the digital divide (DD). $\mathrm{DD}$ is defined as a digitally cognitive difference between each internet user and individual who do not have the technical abilities to access and conduct with internet technologies. From a comprehensive survey of the latest literatures in DD, DD has been briefly generated from three crucial impacted elements: individual (gender, age, skills, education, and capacity), organizational (race and team features), and social (geographical limitation, economic restriction and national policies) [6]. Moreover, with reference to relative literatures of DD [7-15], there are six specific characteristics of DD: (1) connected subjects: the DD subjective gaps cover individuals, organizations, enterprises, schools, hospitals, countries, and so forth [16]; (2) connected contents: connectivity of DD attributes the demographic and socioeconomic variables, such as income, education, age, and geographic location [17]; (3) connected media: the DD media connectivity obtains from the various devices including fixed or mobile, Internet or telephony, and digital TV; (4) connected methods: intensity to how sophisticated the usages are including mere access, retrieval, interactivity, and innovative contributions [18]; (5) connected goals: purpose as to why individuals and their cohorts are (or not) connecting: reasons individuals are and are not online or utilizing internet technology [19], and (6) connected maneuverability: dynamics to whether the gap of concern will increase or decrease in the future and when the gap of concern would be maximized [20].

Nevertheless, beyond a contiguity of comprehensive surveys in the DD research field, the majority of studies focuses on the discussion of various present situations and problems of DD [21-27]. The interplay between ICT and DD has not been thoroughly discussed in the current management circles in the technology research fields. For this reason, this study creatively adopted three brief perspectives of the Social Cognition Theory (SCT) [28-30]: (1) Individual 


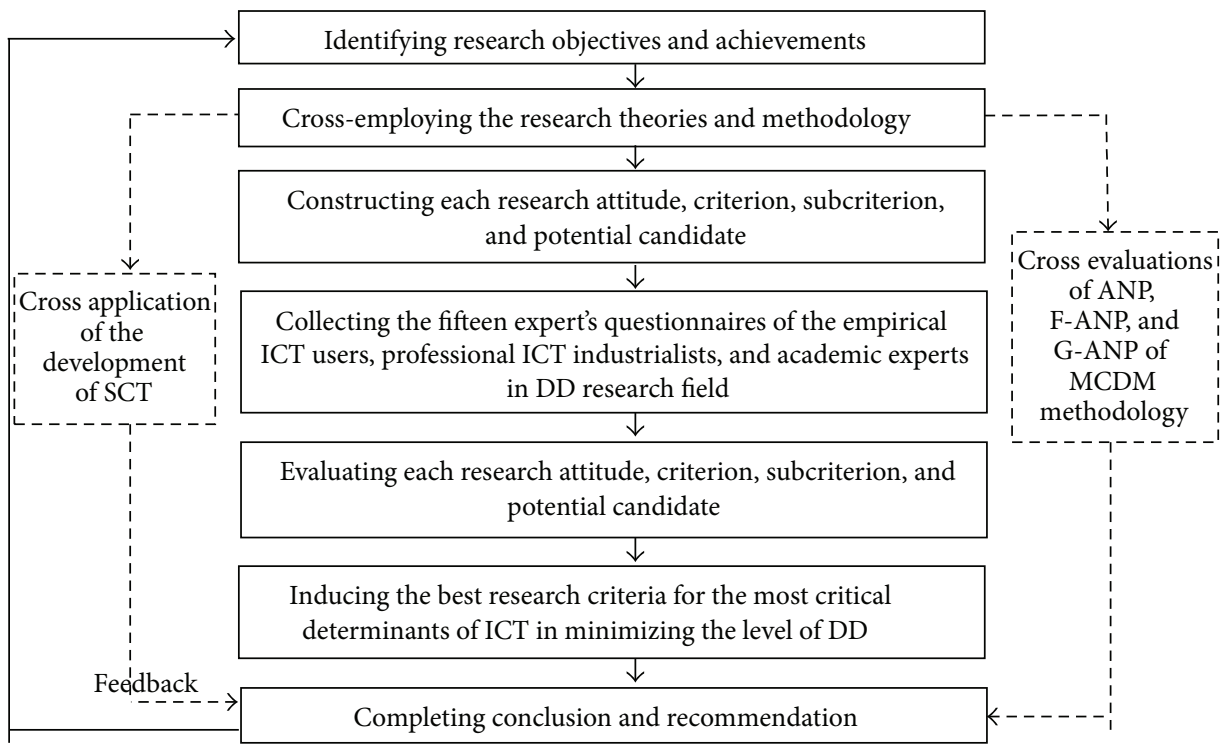

Figure 4: Research design framework.

Behaviorism (ICT Users aspect); (2) Group Organizationism (ICT Industry aspect), and (3) Community Socializationism (ICT Society) into the qualitative measurements in order to strengthen research validity because the characteristics of SCT are to comprehensively discuss and analyze the interactive dependences among ICT users (individual: cognitivism and behaviorism) versus ICT industrials (group: organizationism); ICT industrials (group: organizationism) versus DD research society (socializationism), and DD research society (socializationism) versus ICT users (individual: cognitivism and behaviorism) for discussing the related humanity issues or situation in social science research field. Significantly, SCT has recently been the theoretical mainstream to synthetically assay the interactive dependences between social science and other technologies, especially the interplays among the individuals, and society [31]. Significantly, in order to reinforce research reliability, this research innovatively consolidate the Fuzzy Theory (FT) and the Grey Relation Theory (GRT) of the multiple criteria decision making (MCDM) methodology [32] into the analytical network process (ANP) for hierarchically construct the fuzzyanalytical network process (F-ANP) and the fuzzy-analytical network process (G-ANP) in the quantitative measurements in order to comprehensively detect, identify, and evaluate the most potential key-determinants and interactive influences of ICT in the minimization of the level of DD [33].

\section{Research Design}

2.1. Research Framework and Hierarchy. After making a comprehensive survey of a series of relative literatures of SCT, ANP model, and MCDM methodology, the research design framework was systematically designed in Figure 4 including seven measured activities: constructing, confirming, identifying, collecting, evaluating, inducing, and integrating. After establishing Figure 4, this research comprehensively investigates and organizes recent academic researches and empirical reports in the related ICT field to evaluate the most influenced fifteen ICT technological elements (subcriteria), which are then categorized into four assessable groups (criteria). Consequently, according to Figure 4 and those critical evaluated criteria, sub-criteria, and candidates, the research evaluated hierarchy was comprehensively constructed in Figure 5. The synthetically comparative index numbers (SCIN) $\left(D_{\mathrm{P}}, D_{\mathrm{CB}}\right.$, and $D_{\mathrm{SC}}$ ) of three potential candidates consisting of (1) ICT which can positively minimize the level of connectpurposes digital divide (ICTCPMDD); (2) ICT which can possibly minimize the level of connect-media digital divide (ICTCPOMDD), and (3) ICT which can negatively minimize the level of connect-operation digital divide (ICTCPNMDD) were cross-analyzed by the weighted measurements of the pair-wise questionnaire among each appraised attitude, assessed criterion, and evaluated subcriterion in order to discover the best solution of this research topic.

2.2. Critical ICT Determinants. The first assessable criteria group defines the consolidated connection technology (CTT) expressed in the ICT characteristics of the ubiquity and information and CTT consists of (1) Wideget function (WF): the networking websites of ICT create the new technologies to fix with other consumer electronic devices interface, such as the users are able to utilize the wireless internet function to surf the websites and to operate the e-mail function on their own mobile phone which results in the networking of personal users' information so that it can be sent to other users of mobile phone [34, 35]; (2) Application Programming Interface (API): the networking websites of ICT open the "encoding functions" of website programs to increase function and application in order to attract more users and then put advertisement of corporate products or services in this interacted interface, such as Wikipedia (the free encyclopedia) and Facebook [36]; (3) Cloud Computing Function (CCF): the virtual cloud-computing function technology offers the complex computing function for each ICT user 


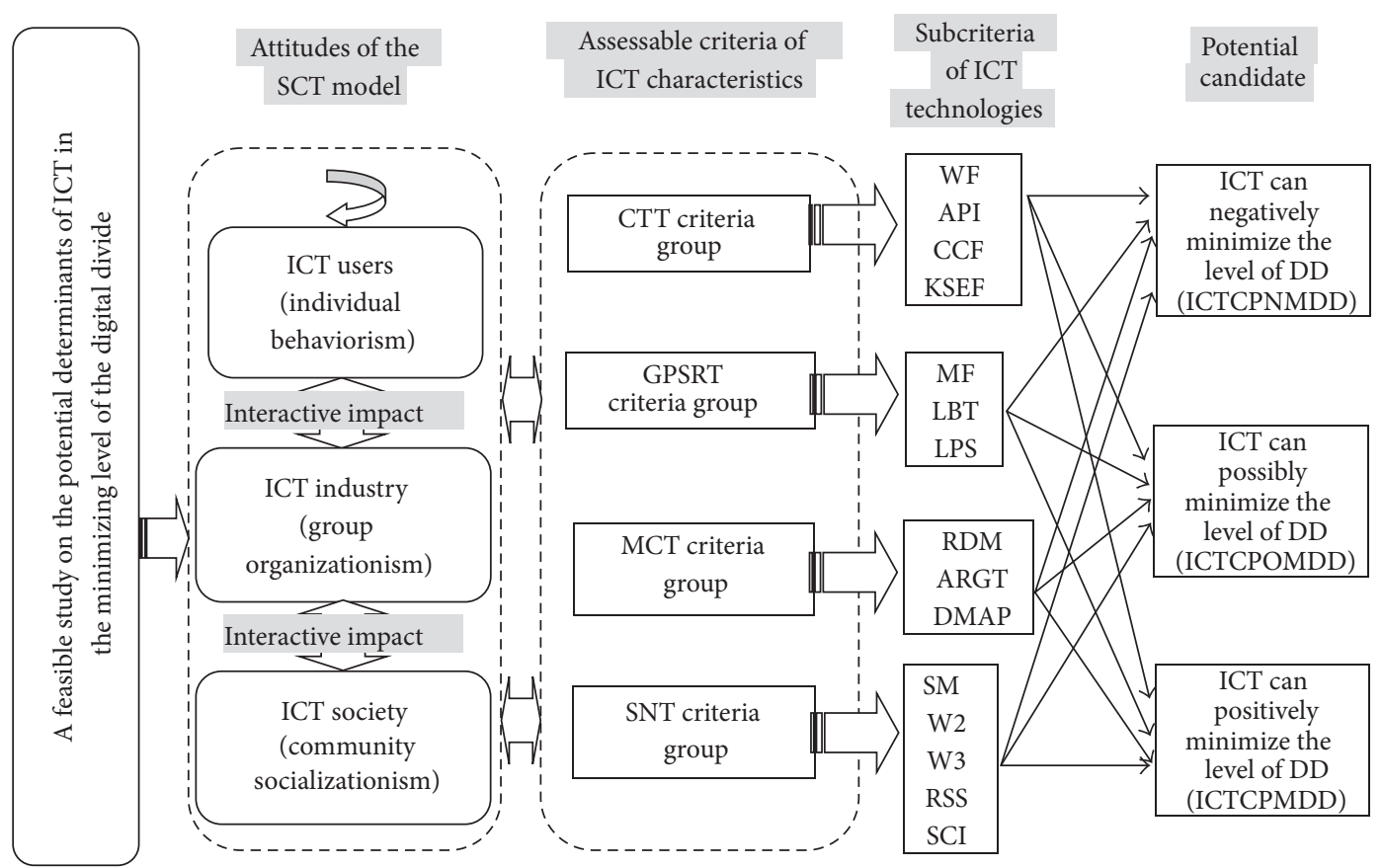

FIGURE 5: Research evaluated hierarchy.

according to the rapid growth of wireless-service and highspeedy transmission with the largest bandwidth [37], and (4) Keyword Search Engine Function (KSEF): the networking websites of ICT produces alluring key-word search messages in the first window search in order to attract each user to search the related information [38]. Moreover, the second assessable criteria group is the GPS position technology (GPSRT) displayed the ICT technological characteristics of location-based service and embraces (1) Metaverse Function $(M F)$ : the networking websites of ICT are able to utilize the diversified virtual-reality functions to construct the augmented reality positioning located presentation to fascinate each users such as 3D expression [39]; (2) Individual Behavior Targeting (LBT): the ICT industrialists are able to gather the located preferred information from each ICT user in order to initiate the absorptive subject and content of networking websites to increase uses [40], and (3) Individual Location Service (LPS): the networking websites of the ICTs provide the specific GPS guide and positioning function in order to allow each ICT user the convenience to upload and download personal real-time located information [41]. Subsequently, the third assessable criteria group is the mobile connection technology (MCT) and MCT is the ICT characteristic of mobility and further comprehends (1) Real-time Direct Messages $(R D M)$ : the social networking communities actively forward periodical and irregular messages and information of each community member to the users through the online transmission service of the consumer electronic devices; (2) Alternate Reality Games Interface (ARGT): the networking websites of the ICT create the virtual games for attracting more users for configuring commercials and advertisements of corporate products or services [42], and (3) Diversified Mobile Applications (DMAP): in term of the popularization of smart phone, each user has commenced to request more applications for entertainments comprised of the media-play, vide-games, and media-telecommunication. Therefore, much more ICT engineers are devoted to research and develop the mobile-AAP software to meet the users' demands. Consequently, the fourth assessable criteria group is the social networking technology (SNT) expressed ICT characteristics of the individualization and congregation and comprises (1) Social Media (SM): the networking websites of the ICT provide various interactive social media interfaces, such as JAVA, Real Audio, Real Video, Shockwave, and so forth, in order to exchange media data of each user, such as YouTube, Google media, and Yahoo Photos, in order to complete transaction in the networking website, (2) Web 2.0 (W2): the networking websites of the ICT develop the interacted interface to increase users' satisfaction because each user is able to change from passive readers to active creators [43], (3) Web 3.0 (W3): the networking websites of the ICT currently research and develop the new interacted interface technology for alluring more ICT users, such as virtual communication interface and three digital or four digital interface technologies, (4) Really Simple Syndication (RSS): the networking websites of ICT resupplying function of regular subscription to each ICT user in order to obtain the opportunities to put dynamically and statically individual information to each social community member [44], and (5) Social Community Integration (SCI): the networking websites of the ICT supply the "social congregating function" to connect each ICT user in order to construct their owned virtual communicated society, such as Blogs, Twitter, and Facebook [45].

2.3. Measured Model and Statistic Method. In order to induce the best potential determinant of ICT in minimizing the level of DD, this study cross-employs the three analytical 
perspectives of SCT and ANP model to construct the most effective analytical model (F-ANP and G-ANP evaluated models) because SCT has recently become the mainstream theory to expound the relative issues regarding comprehensive interplays and relationships among individual, group, and society as a whole in the complicatedly contemporary society [46]. Besides, as for the relative literatures on ANP model, [47] invented the hierarchically analytical ANP model to measure the experts' questionnaire weights through the positive reciprocal matrix and supermatrix measurements, the Delphi method, and the brainstorm approaches under the comprehensive, limited-resource, and difficult decision conditions. In succession, [48] stated the typical measurements process that overall related-impacted factors are categorized into four groups and, then, according to the patterns of ANP model, these related-impacted factor-groups are decomposed as third hierarchy of criteria of assessments. In terms of the basic concept of ANP model, ANP model is able to be applied not only to clearly establish the synthetic hierarchy-relations between each assessable criterion but also to distinctly point out the cross analytical consequence. The related-impacted factors are also decomposed as fourth hierarchy of each criterion and subcriterion [49]. Furthermore, on account of evaluated statistic measurements of ANP model, "once the pairwise comparison is conducted and completed, the local priority vector $\mathbf{w}$ (eigenvector) is computed as the unique solution" and the $w$ is the represented priority vector $\mathbf{w}$ (relative weights). In [50] were invented the two-stage algorithms $\left(R w=\lambda_{\max } w\right.$ and $\left.w_{i}=\sum_{j=1}^{m}\left(R i j / \sum_{i=1}^{m} R i j\right) / \mathrm{m}\right)$ and in each pairwise comparison between each criterion the consistency of compared factors will match transitivity to fulfill the collected representativeness of professional expert's opinion. The consistency index (C.I. $=\left(\lambda_{\max }-n\right) /(n-1)$, "C.I.") which is exactly considered in each pairwise matrix and the consistency ratio (C.R. = C.I./R.I., "C.R.") which is estimated with C.I. and the random index (R.I) acquired from the statistic table of random index figure. The most critical acceptable regulation is that the evaluated numbers of C.R. and C.I. both must be smaller than 0.1 [51].

Subsequently, in order to increase the research validity in the research questionnaires, [52] induced the fuzzy set which was based on two characteristics (membership degree and membership function) of the fuzzy set theory for substituting the crisp set of traditional mathematics which can set up the uncertain and fuzzy research problems. In the hierarchical relations in the last level, each potential supplier has to fit match each assessable subcriterion matched in each evaluated criterion through pairwise compared criteria of each subcriteria following [53]. Therefore, as for the integration between the fuzzy theory and the ANP, each expert can give the weights $\left(W_{1}, W_{2}, \ldots, W_{n}\right)$ of each pattern, criteria, and subcriteria and based on the concept of two-triangles de-fuzzy, the total fuzzy assessable numbers (TFAN) are calculated by TFAN $=\sqrt[n]{\prod_{i=1}^{n} W_{i}}$.

In order to reflect the comparative score for the three types of corporate demand patterns, the measured formula (1) is applied to compute the comprehensively comparative related priority weight $\mathbf{w}$ (eigenvector) in the matrix.
Consequently, the appropriate relations are selected by calculating the comparatively synergized index which combines the "weighted product" [54] and the "numbers of similarity measure ("S[A,B]")". Further, in terms of defuzzification from the aspect of effective order, the similarity measure $(S[A, B])$ as expressed in the measured formula (1) is utilized by measuring the calculation of symmetrical triangular fuzzy numbers between two measured vectors $\left(A_{1}=\left(c_{1}, a_{1}, b_{1}\right)\right.$ and $\left.A_{2}=\left(c_{2}, a_{2}, b_{2}\right)\right)[55]$ :

$$
S\left[V_{1}, V_{2}\right]= \begin{cases}1 \\ \operatorname{Exp}\left(-\frac{d^{2}}{\alpha}\right), & \text { if } V_{1} \neq V_{2},\end{cases}
$$

where $d^{2}\left(A_{1}, A_{2}\right)=\left(a_{1}-a_{2}\right)^{2}=\left[\left(\left(c_{1}+a_{1}\right)-\left(c_{2}+a_{2}\right)\right)^{2} / 4\right]+$ $\left[\left(\left(b_{1}+a_{1}\right)-\left(b_{2}+a_{2}\right)\right)^{2} / 4\right], \alpha=\left(D^{*}+D_{*}\right) / 2+\left(\left|c_{1}-c_{2}\right|+\mid b_{1}-\right.$ $\left.b_{2} \mid\right) / 8, D^{*}=\left|\left(a_{1}+b_{1}\right)-\left(a_{2}+b_{2}\right)\right| / 2, D_{*}=\left|\left(a_{1}+c_{1}\right)-\left(a_{2}+c_{2}\right)\right| / 2$.

Furthermore, according to the concept of the Fuzzy Theory (FT), [56] further induced the more effect and efficient grey system theory (GST) to measure the uncertain and fuzzy situation. Reference [57] integrated and applied the related approaches, structure measure, and model-making method to induce grey system established between block system and white system, in order to integrate the indefinite research data to become useful research data which reach the research purposes of managerial control, decision-making, and foreseeing. The main function of GST is to not only measure the level of relation between each influenced factors under uncertain circumstances but to also utilize the trend level among uncertain and incomplete information of each influenced factor to quantify the level of relation in order to appraise the dependence or independence relations between each influenced factor in the three kinds of analytical goals: (1) the Larger the Better $\left(x_{i}^{*}=\left(x_{i}^{(0)}(k)-\min x_{i}^{(0)}(k)\right) /\left(\max x_{i}^{(0)}(k)-\right.\right.$ $\left.\min x_{i}^{(0)}(k)\right)$, "LTB"); (2) the Smaller the Better $\left(x_{i}^{*}=\right.$ $\left(\min x_{i}^{(0)}(k)-x_{i}^{(0)}(k)\right) /\left(\max x_{i}^{(0)}(k)-\min x_{i}^{(0)}(k)\right)$, “STB”), and (3) the Nominal the Best $\left(x_{i}^{*}=1-\left\{\left|x_{i}^{(0)}(k)-\mathrm{OB}\right| /\right.\right.$ $\left.\max \left(\max \left[x_{i}^{(0)}(k)\right]-\mathrm{OB}, \mathrm{OB}-\min \left[x_{i}^{(0)}(k)\right]\right)\right\}$, “NTB”). In specific, the $x_{i}^{(0)}(k)$ represents original data; $x_{i}^{*}$ represents date after grey relation system analysis; $\min x_{i}^{(0)}(k)$ represents the minimum of original data; $\max x_{i}^{(0)}(k)$ represents the maximum of original data. Eventually, in the hierarchical relations in the last level, each potential candidate has to match each assessable subcriterion matched in each evaluated criterion through pairwise compared matrixes. Hence, in order to reflect the comparative score for the three kinds of candidates in problem solving the research issue, (2) of the "Synthetically Comparative Index Numbers (SCIN)" is applied to compute the comprehensively comparative related priority weightw (eigenvector) in the matrix and SCIN which is defined by

$$
\operatorname{SCIN}_{i}=\sum_{j=1}^{s} \sum_{k=1}^{k j} P_{j} T_{k j} R_{i k j}
$$

With respect to (2), where $D_{i}$ is the importance of related priority weight $\mathbf{w}$ (eigenvector) for assessable criterion $j$; 
TABLE 1: The grey transformation.

\begin{tabular}{lccccc}
\hline Level of importance (language powers) & Equal & Little importance & Important & Very important & Extremely important \\
\hline Figure of grey set system in GRA & 0.091 & 0.283 & 0.5 & 0.717 & 0.919 \\
\hline
\end{tabular}

TABLE 2: The complete SCIN of ANP, F-ANP, and G-ANP.

\begin{tabular}{|c|c|c|c|c|c|c|c|}
\hline \multirow[b]{2}{*}{ Criteria } & \multirow[b]{2}{*}{ Subcriteria } & \multicolumn{2}{|r|}{ ICTCPMDD } & \multicolumn{2}{|r|}{ ICTCPOMDD } & \multicolumn{2}{|r|}{ ICTCPNMDD } \\
\hline & & Weights & Evaluated score & Weights & Evaluated score & Weights & Evaluated score \\
\hline \multirow{4}{*}{ CTT criteria group } & WF & 0.1695 & $(0.0758,0.0806,0.0853)$ & 0.2895 & $(0.1328,0.1376,0.1423)$ & 0.541 & $(0.2096,0.2572,0.2619)$ \\
\hline & API & 0.1492 & $(0.0662,0.0709,0.0757)$ & 0.2816 & $(0.1291,0.1339,0.1386)$ & 0.5692 & $(0.2230,0.2705,0.2753)$ \\
\hline & $\mathrm{CCF}$ & 0.1588 & $(0.0707,0.0755,0.0802)$ & 0.3015 & $(0.1385,0.1433,0.148)$ & 0.5397 & $(0.209,0.2565,0.2613)$ \\
\hline & KSEF & 0.153 & $(0.0680,0.0727,0.0775)$ & 0.2977 & $(0.1368,0.1415,0.1463)$ & 0.5492 & $(0.2135,0.2611,0.2658)$ \\
\hline \multirow{3}{*}{ GPSRT criteria group } & MF & 0.1615 & $(0.0720,0.0768,0.0815)$ & 0.2973 & $(0.1366,0.1413,0.1461)$ & 0.5412 & $(0.2097,0.2572,0.262)$ \\
\hline & LBT & 0.1711 & $(0.0766,0.0813,0.0861)$ & 0.2759 & $(0.1264,0.1311,0.1359)$ & 0.553 & $(0.2153,0.2628,0.2676)$ \\
\hline & LPS & 0.1662 & $(0.0439,0.0468,0.0496)$ & 0.2813 & $(0.0763,0.0791,0.0819)$ & 0.5525 & $(0.1273,0.1554,0.1582)$ \\
\hline \multirow{5}{*}{ MCT criteria group } & $\mathrm{RDM}$ & 0.1635 & $(0.0432,0.046,0.0488)$ & 0.2786 & $(0.0755,0.0784,0.0812)$ & 0.5579 & $(0.1288,0.1569,0.1597)$ \\
\hline & ARGT & 0.1535 & $(0.0227,0.0243,0.0259)$ & 0.2913 & $(0.0445,0.0461,0.0477)$ & 0.5553 & $(0.0721,0.0879,0.0895)$ \\
\hline & DMAP & 0.1456 & $(0.0381,0.041,0.0438)$ & 0.2743 & $(0.0743,0.0772,0.08)$ & 0.5801 & $(0.135,0.1632,0.166)$ \\
\hline & SM & 0.1561 & $(0.0231,0.0247,0.0263)$ & 0.2976 & $(0.0455,0.0471,0.0487)$ & 0.5463 & $(0.0706,0.0865,0.088)$ \\
\hline & W2 & 0.1616 & $(0.024,0.0256,0.0272)$ & 0.2712 & $(0.0413,0.0429,0.0445)$ & 0.5672 & $(0.0739,0.0898,0.0913)$ \\
\hline \multirow{3}{*}{ SNT criteria group } & W3 & 0.165 & $(0.0132,0.014,0.0149)$ & 0.3021 & $(0.0249,0.0257,0.0266)$ & 0.5329 & $(0.0369,0.0454,0.0462)$ \\
\hline & RSS & 0.1601 & $(0.0128,0.0136,0.0145)$ & 0.3023 & $(0.0249,0.0257,0.0266)$ & 0.5377 & $(0.0373,0.0458,0.0466)$ \\
\hline & SCI & 0.1618 & $(0.0129,0.0138,0.0146)$ & 0.3064 & $(0.0252,0.0261,0.0269)$ & 0.5319 & $(0.0368,0.0453,0.0461)$ \\
\hline \multicolumn{2}{|c|}{ SCIN(ANP) ${ }^{*}$} & & 0.1599 & & 0.2885 & & 0.5516 \\
\hline \multicolumn{2}{|c|}{$\operatorname{SCIN}(\mathrm{F}-\mathrm{ANP})^{* *}$} & & 0.2958 & & 0.3269 & & 0.3771 \\
\hline \multicolumn{2}{|c|}{$\operatorname{SCIN}(\mathrm{G}-\mathrm{ANP})^{* * *}$} & & 0.2115 & & 0.3094 & & 0.4791 \\
\hline
\end{tabular}

${ }^{*}$ The complete SCINs of ANP model was standardized among each the complete SCIN of the three assessable candidates.

*** The complete SCINs of F-ANP model was standardized among each the complete SCIN of the three assessable candidates.

*** The complete SCINs of G-ANP model was standardized among each the complete SCIN of the three assessable candidates.

$T_{k j}$ is the importance of related priority weight $\mathbf{w}$ (eigenvector) for assessable characteristic $k$ of criterion $j$, and $R_{i k j}$ is the important potential candidate $i$ (business website $i$ ) on the characteristic $k$ of criterion $j$.

\section{Empirical Measurements}

3.1. Questionnaire Scale. Furthermore, with reference to the fundamentally assessable model characteristics of the ANP approach, the pairwise comparisons at each level are evaluated using a five-level of related interdependence and importance ranging from equally important (1) to extremely important (5) that follows the concept of the Likert's scale. Hence, the measurements of the fuzzy transitivity, comparing weights principle, evaluating criteria, and estimating positive reciprocal matrix and supermatrix between each assessable attitude, criterion, subcriterion, and potential candidate all have been completely calculated through the use of a fivelevel questionnaire.

3.2. Surveyed Collection. On an account of the cross applications of SCT and MCDM methodology, the entire survey data collected was from the opinions of empirical ICT users, professional ICT industrialists, and academic experts in DD research field in order to deal with retrospective crosssectional analysis of the hierarchical relations for organizing the assessed hierarchy by testifying each the related impacted criterion from collecting influenced elements [58]. As for the questionnaire scale, the entire surveyed collection was derived from professional experts who understand the flourishing of research and development in the ICT technology and the digital-divide level fields. Therefore, [59] discovered that there are the least errors of validity and reliability in the Delphi method when collected questionnaires come from, at least, over 10 professional interviewees. For this reason, this research adapts the Delphi method to collect questionnaires and comments from fifteen experts who are categorized into three groups. The first group represents five experienced ICT users who have published a professional column in the ICT magazines. The second group consists of five empirical senior managers who have over ten years of working experience in the ICT industries. Lastly, the third group comprises of five academic scholars with at least 10 years of extensive research in relative ICT and DD researches fields. In order to distinctly discover the true comments of the surveyed questionnaire of the interviewed experts without linguistic confusion, this research further utilizes the five-level quantified figures of evaluation scales of Table 1 between languages of interviewees of pairwise in assessment of G-ANP model.

3.3. Measured Results of Questionnaire Weights. As for the research design, research framework (Figure 4), and research hierarchy (Figure 5), the systematical and hieratical calculations of complete importance of related priority weights $\mathbf{w}$ (eigenvector) of the complete SCINs of ANP, F-ANP, and GANP models are illustrated in Table 2. Significantly, a series of 
measurements of Table 2 indicates two distinct consequences. First, the highest SCINs score of ANP, F-ANP, and G-ANP models is $0.5516,0.3771$, and 0.4791 , respectively, and all are located in the ICTCPOMDD column. Secondly, the highest evaluated weighted score of assessed criteria of 0.5801 is located in the Diversified Mobile Applications (DMAPP) column.

\section{Discussion and Conclusion}

These days, with the swift development of ICT, DD has played a critically decisive role not only in the current IT field but also in the human behavior field because each IT user is able to gather and forward the numerous data and information to everywhere in the overall world by means of use of ICT wireless transmission technology. Therefore, this research systematically employed three analytical perspectives (empirical ICT users, professional ICT industrialists and academic experts in DD research field) of SCT but it also hierarchically constructed F-ANP and G-ANP evaluation models to comprehensively assay the interactive relationships and dependences between ICT and DD by reidentifying the most potential determinants of ICT. According to the measured results of the complete importance of related priority weights w (eigenvector) of the complete synthetically comparative index numbers (SCIN) in ANP, F-ANP, and G-ANP models, ICT can positively minimize the level of DD. Significantly, the comments from experts that participated in questionnaire indicated that there are still some other human-control elements to be able to decisively influence and determine the level of DD such as IT developed policies of national head the administration, capital constructions of IT, and wireless transmission technologies. Hence, based on the measured results, ICT can indeed prove determinative influences and interplays in the level of DD which means that the undeveloped, developing, and emerging regions are apparently able to minimize the level of DD by means of the ICT development. The valuable contribution of this research is that the Diversified Mobile Applications (DMAPP) is the most potential determinant of ICT in minimizing the level of DD which means that extensive ICT users can focus on the smart-phone application (APP) services of telecommunication technology more than traditional computer devices of IT technology because they can easily and conveniently upload and download diversified information in anytime and at anywhere through their smart mobile phone. Beyond this research, in order to pursue higher research representativeness, reliability, and validity, more evaluated ICT criteria, measured models of MCDM methodology, and surveyed expert questionnaires are majorly developed factors in the future research direction.

\section{Conflict of Interests}

The author declares that there is no conflict of interests regarding the publication of this paper

\section{References}

[1] I. Qureshi and D. Compeau, "Assessing between-group differences in information systems research: a comparison of covariance- and component-based SEM," MIS Quarterly, vol. 33, no. 1, pp. 199-216, 2009.

[2] L. Egghe, "The hirsch index and related impact measures," Annual Review of Information Science and Technology, vol. 44, no. 1, pp. 65-114, 2010.

[3] H. Lu and K. L. Hsiao, "Gender differences in reasons for frequent blog posting," Online Information Review, vol. 33, no. 1, pp. 135-156, 2009.

[4] M. Hassenzahl and N. Tractinsky, "User experience-a research agenda," Behaviour and Information Technology, vol. 25, no. 2, pp. 91-97, 2006.

[5] M. Hassenzahl and D. Ullrich, "To do or not to do: differences in user experience and retrospective judgments depending on the presence or absence of instrumental goals," Interacting with Computers, vol. 19, no. 4, pp. 429-437, 2007.

[6] C. Y. Chiu and E. Weng, "Integration of fuzzy multi-criteria decision making and grey relation for job oriented heuristics scheduling system," National Taipei University of Technology School Press, Taipei, Taiwan, 1994.

[7] R. Cullen, "Addressing the digital divide," Online Information Review, vol. 25, no. 5, pp. 311-320, 2001.

[8] H. Bonfadelli, “The Internet and knowledge gaps: a theoretical and empirical investigation," European Journal of Communication, vol. 17, no. 1, pp. 65-84, 2002.

[9] J. De Hann, "A multifaceted dynamic model of the digital divide," IT \& Society, vol. 1, no. 7, pp. 66-88, 2004.

[10] G. Chowdury, "Access to information in digital libraries: users and digital divide," in Proceedings of the International Conference on Digital Libraries, New Delhi, India, February 2004, http://strathprints.strath.ac.uk/2622/1/strathprints002622.pdf.

[11] C. Yanhong, "Shuzi honggou wenti yanjiu shuping (a review of digital divide researches)," Qingbao Zazhi (Journal of Information), vol. 2, pp. 15-45, 2005.

[12] B. Luyt, "Who benefits from the digital divide?" First Monday, vol. 9, no. 8, 2004, http://firstmonday.org/issues/issue9. 8luyt/index.html.

[13] M. Warschauer, Technology and Social Inclusion: Rethinking the Digital Divide, The MIT Press, Cambridge, Mass, USA, 2004.

[14] BBC, "Digital divide could be deepening," BBC News, 2006, http://philbradley.typepad.com/phil_bradleys_weblog/2006/10/ bbc_news_digita.html.

[15] S. Aqili and A. Moghaddam, "Bridging the digital divide: the role of librarians and information professionals in the third millennium," Electronic Library, vol. 26, no. 2, pp. 226-237, 2008.

[16] M. D. Chinn and R. W. Fairlie, The Determinants of the Global Digital Divide: A Cross-Country Analysis, Economic Growth Center, 2004, http://www.econ.yale.edu/growth_pdf/cdp881.pdf.

[17] C.-Y. Huang and H.-N. Chen, "Global digital divide: a dynamic analysis based on the bass model," Journal of Public Policy and Marketing, vol. 29, no. 2, pp. 248-264, 2010.

[18] H. Galperin, "Goodbye digital divide, hello digital confusion? A critical embrace of the emerging ICT4D consensus," Information Technologies \& International Development, vol. 6, pp. 53-55, 2010. 
[19] Science and Development Network, How mobile phones increased the digital divide, 2014, http://www.scidev.net/global/ data/scidev-net-at-large/how-mobile-phones-increased-the-digital-divide.html.

[20] N. E. Miller and J. Dollard, Social Learning and Imitation, Yale University Press, New Haven, Conn, USA, 1941.

[21] P. Norris, "The worldwide digital divide; information poverty and development," in Proceedings of the Annual Meeting for the Political Studies Association of the UK, London, UK, April 2000.

[22] W. Chan and B. Wellman, "The global digital divide-within and between countries," IT \& Society, vol. 1, no. 7, pp. 39-45, 2004.

[23] S. Hubregtse, "The digital divide within the European Union," New Library World, vol. 106, no. 3-4, pp. 164-172, 2005.

[24] X. Hao and S. Chao, "Factors affecting internet development: an Asian survey," First Monday, vol. 9, no. 2, 2004.

[25] C. Guðmundsdóttir, "Approaching the digital divide in South Africa," in Proceedings of the NETREED Conference, Beitostølen, Norway, December 2005, http://www.netreed.uio.no/conferences/conf2005/GretaGudmundsdottir.pdf.

[26] Z. Xinhong, “The 2008 report of China’s digital divide," Tech. Rep., Electronic Government, 2008.

[27] Institute for Prospective Technological Studies Digital Economy Working Paper, "Has the Digital Divide Been Reversed? evidence from Five EU Countries,” 2013, http://ftp.jrc.es/EURdoc/JRC80782.pdf.

[28] S. P. Martin and J. P. Robinson, "The income digital divide: trends and predictions for levels of internet use," Social Problems, vol. 54, no. 1, pp. 1-22, 2007.

[29] D. Fallows, "China's online population explosion; what it may mean for the Internet globally...and for the US. Pew Internet and American Life Project," 2007, http://uploadi.www.ris.org/ editor/1184918816China_Internet_July_2007.pdf.

[30] Digital divide: What It Is and Why It Matters, http://www .digitaldivide.org/dd/digitaldivide.html.

[31] M. J. Sanchez-Franco and J. L. Roldán, "Expressive aesthetics to ease perceived community support: exploring personal innovativeness and routinised behaviour as moderators in Tuenti," Computers in Human Behavior, vol. 26, no. 6, pp. 1445-1457, 2010.

[32] L. Bornmann, R. Mutz, and H.-D. Daniel, "The h index research output measurement: two approaches to enhance its accuracy," Journal of Informetrics, vol. 4, no. 3, pp. 407-414, 2010.

[33] M. F. Guillén and S. L. Suárez, "Explaining the global digital divide: economic, political and sociological drivers of crossnational internet use," Social Forces, vol. 84, no. 2, pp. 681-708, 2005.

[34] C. Flavián, M. Guinalíu, and R. Gurrea, “The role played by perceived usability, satisfaction and consumer trust on website loyalty," Information and Management, vol. 43, no. 1, pp. 1-14, 2006.

[35] E. Deutskens, K. de Ruyter, and M. Wetzels, "An assessment of equivalence between online and mail surveys in service research," Journal of Service Research, vol. 8, no. 4, pp. 346-355, 2006.

[36] C. Flavián, R. Gurrea, and C. Orús, “The effect of product presentation mode on the perceived content and continent quality of web sites," Online Information Review, vol. 33, no. 6, pp. 1103$1128,2009$.

[37] L. Zeng and G. Salvendy, "How creative is your website," in Proceedings of the 2nd International Conference on Applied
Human Factors and Ergonomics (AEI '08), vol. 1, pp. 1-10, Las Vegas, Nev, USA, 2008.

[38] R. Pak, S. Pautz, and R. Iden, "Information organization and retrieval: an assessment of taxonomical and tagging systems," Cognitive Technology, vol. 12, no. 1, pp. 31-44, 2007.

[39] D. G. Campbell, "A phenomenological framework for the relationship between the Semantic Web and user-centered tagging systems," in Proceedings of the 17th ASIST Classification Research Workshop, Advances in Classification Research, J. Furner and J. T. Tennis, Eds., vol. 17, pp. 1-17, Austin, Tex, USA, 2006.

[40] M. Hassenzahl and N. Tractinsky, "User experience-a research agenda," Behaviour \& Information Technology, vol. 25, no. 2, pp. 91-97, 2006.

[41] M. E. Kipp, "Complementary or discrete contexts in online indexing? A comparison of user, creator, and intermediary keywords," Canadian Journal of Information and Library Science, vol. 29, no. 4, pp. 419-436, 2006.

[42] Y. J. Wang, M. D. Hernandez, and M. S. Minor, "Web aesthetics effects on perceived online service quality and satisfaction in an e-tail environment: the moderating role of purchase task," Journal of Business Research, vol. 63, no. 9-10, pp. 935-942, 2010.

[43] P. Anderson, What is Web 2.0? Ideas, technologies and implications for education, 2007, http://www.jisc.ac.uk/media/documents/techwatch/tsw0701b.pdf.

[44] L. Zeng, G. Salvendy, and M. Zhang, "Factor structure of web site creativity," Computers in Human Behavior, vol. 25, no. 2, pp. 568-577, 2009.

[45] K. Miller, Communication Theories: Perspectives, Processes, and Contexts, McGraw-Hill, New York, NY, USA, 2nd edition, 2005.

[46] R. E. Petty, D. T. Wegener, and L. R. Fabrigar, "Attitudes and attitude change," Annual Review of Psychology, vol. 48, no. 1, pp. 609-647, 1997.

[47] T. L. Saaty, Decision Making with Dependence and Feedback: The Analytic Network Process, RWS Publications, Pittsburgh, Pa, USA, 1996.

[48] T. L. Saaty, Multi-Criteria Decision Making: The Analytic Hierarchy Process, RWS Publications, Pittsburgh, Pa, USA, 1998.

[49] J. Sauer and A. Sonderegger, "The influence of prototype fidelity and aesthetics of design in usability tests: effects on user behaviour, subjective evaluation and emotion," Applied Ergonomics, vol. 40, no. 4, pp. 670-677, 2009.

[50] J. Sharit, S. J. Czaja, S. Nair, and C. C. Lee, "Effects of age, speech rate, and environmental support in using telephone voice menu systems," Human Factors, vol. 45, no. 2, pp. 234-251, 2003.

[51] D. R. Millen, J. Feinberg, and B. Kerr, "Dogar: social bookmarking in the enterprise," in Proceedings of the Conference on Computer Human Interaction, pp. 111-120, ACM Press, New York, NY, USA, 2006.

[52] L. A. Zadeh, "Fuzzy sets," Information and Control, vol. 8, no. 3, pp. 338-353, 1965.

[53] L. A. Zadeh, "Fuzzy sets as a basis for a theory of possibility," Fuzzy Sets and Systems, vol. 1, no. 1, pp. 3-28, 1978.

[54] S. H. Chen, H. T. Lin, and H. T. Lee, "Enterprise partner selection for vocational education: analytical network process approach," International Journal of Manpower, vol. 25, no. 7, pp. 643-655, 2004.

[55] M. S. Yang, W. L. Hung, and S. J. Chang-Chien, "On a similarity measure between LR-type fuzzy numbers and its application to database acquisition," International Journal of Intelligent Systems, vol. 20, no. 10, pp. 1001-1016, 2005. 
[56] D. Ju-Long, “Control problems of grey systems," Systems \& Control Letters, vol. 1, no. 5, pp. 288-294, 1982.

[57] J. Deng, "Grey entropy and grey target decision making," Journal of Grey System, vol. 22, no. 1, pp. 1-4, 2010.

[58] M. E. Pullman and M. A. Gross, "Ability of experience design elements to elicit emotions and loyalty behaviors," Decision Sciences, vol. 35, no. 3, pp. 551-576, 2004.

[59] N. Dalkey and O. Helmer, "An experimental application of the Delphi: method to the use of experts," Management Science, vol. 9, no. 3, pp. 458-467, 1963. 


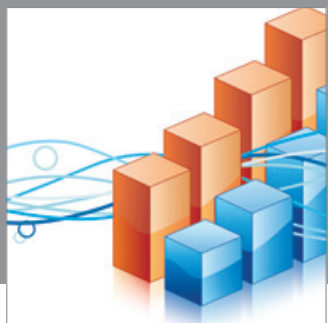

Advances in

Operations Research

mansans

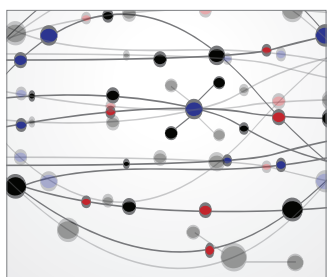

The Scientific World Journal
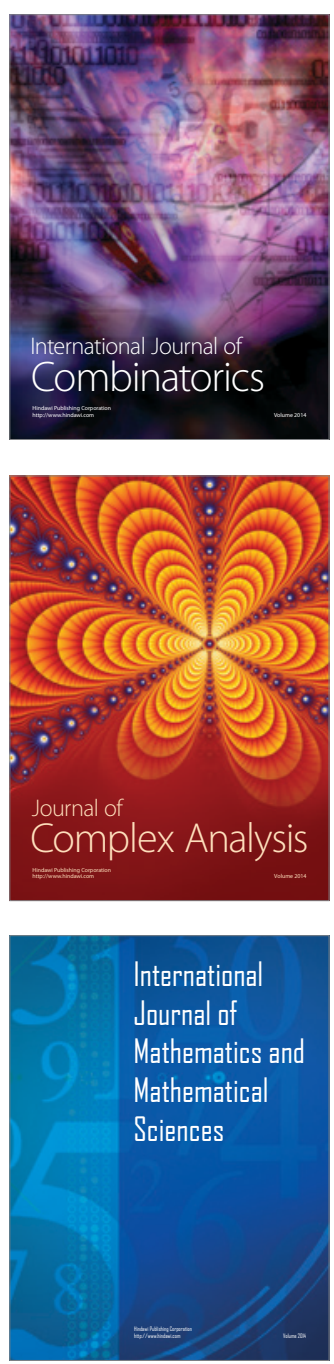
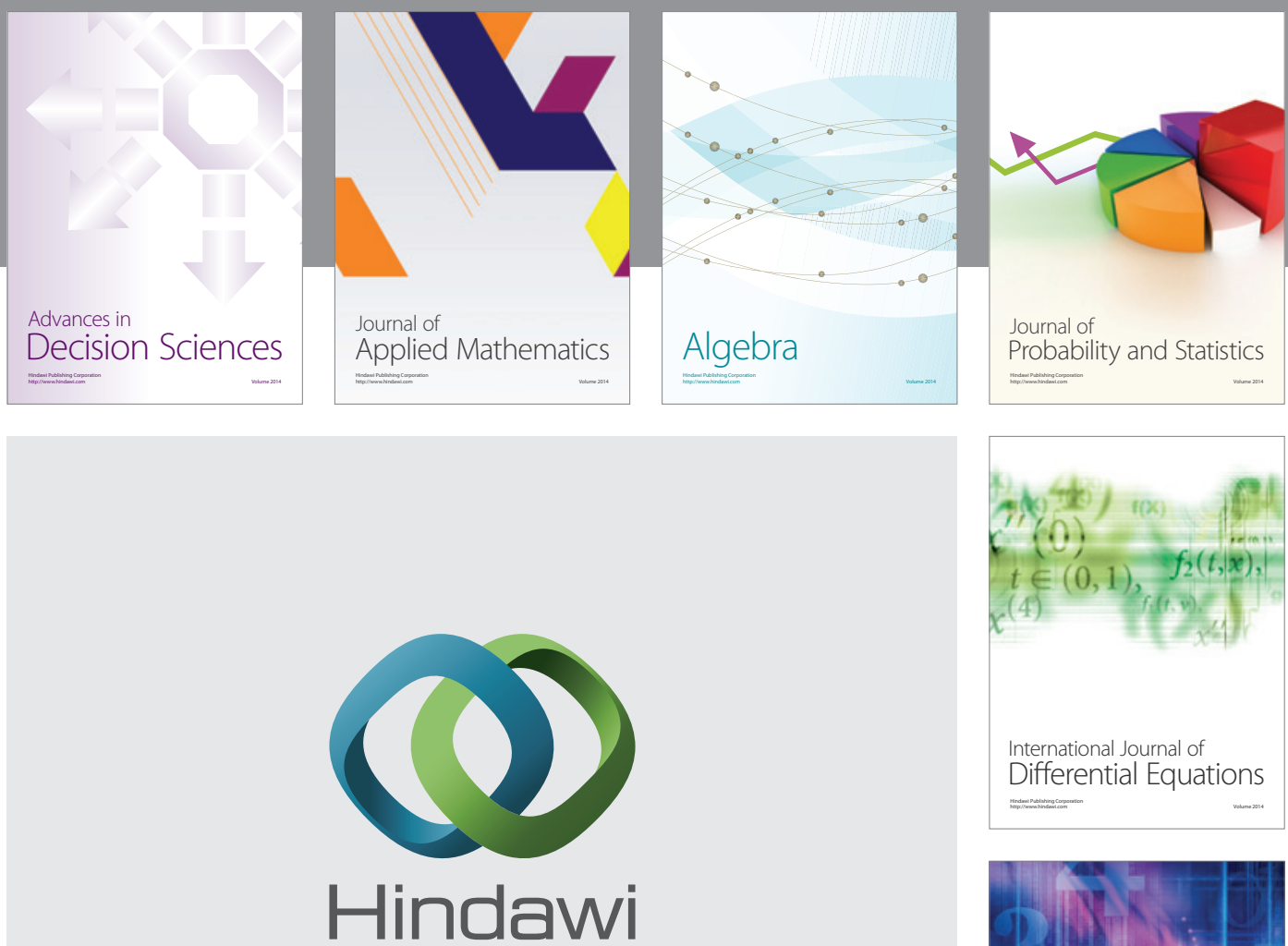

Submit your manuscripts at http://www.hindawi.com
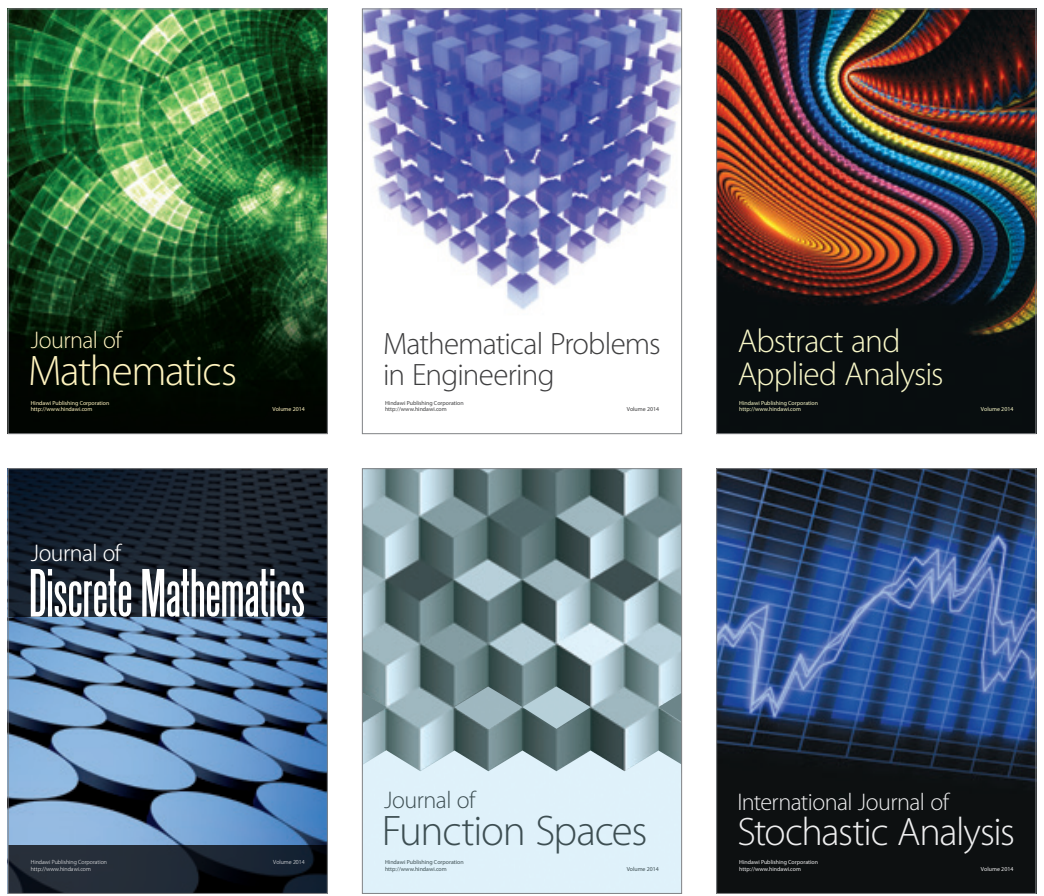

Journal of

Function Spaces

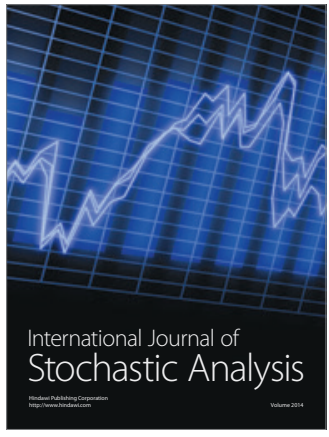

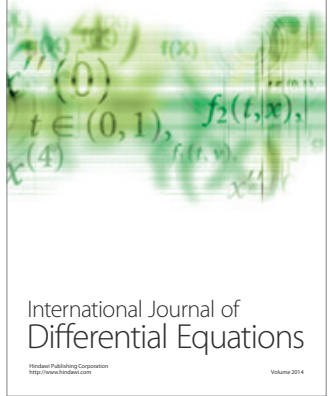
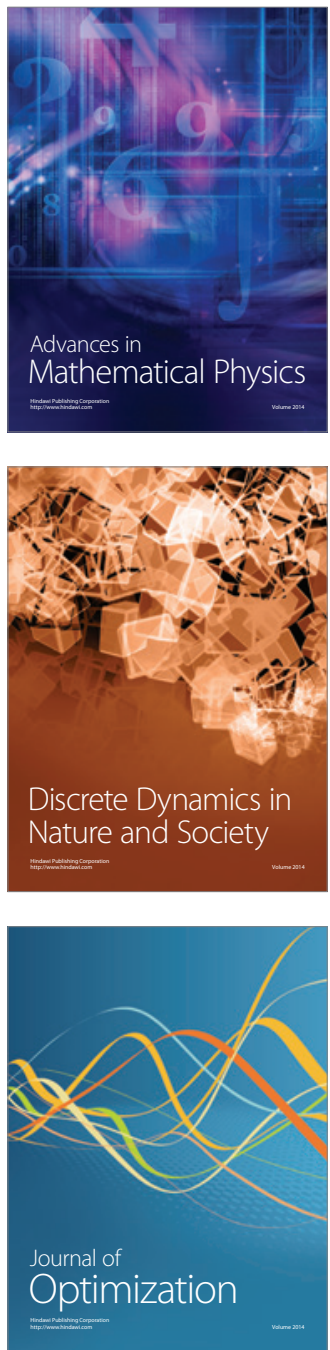